\title{
Editorial
}

\section{Power Options for the Eastern Mediterranean Region}

\author{
Andreas Poullikkas, ${ }^{1,2}$ Philip Demokritou, ${ }^{3}$ Constantinos Sourkounis, ${ }^{4}$ \\ and Yousef Al-Assaf ${ }^{5}$ \\ ${ }^{1}$ American University of Sharjah, Sharjah, UAE \\ ${ }^{2}$ Electricity Authority of Cyprus, 2025 Strovolos, Cyprus \\ ${ }^{3}$ Harvard University, Cambridge, MA, USA \\ ${ }^{4}$ Ruhr University Bochum, Bochum, Germany \\ ${ }^{5}$ Rochester Institute of Technology, Dubai, UAE
}

Correspondence should be addressed to Andreas Poullikkas; apoullik@eac.com.cy

Received 13 May 2013; Accepted 13 May 2013

Copyright (C) 2013 Andreas Poullikkas et al. This is an open access article distributed under the Creative Commons Attribution License, which permits unrestricted use, distribution, and reproduction in any medium, provided the original work is properly cited.

The energy sector is expected to shape the future economic and political relations between countries and multinational companies. This is particularly true in the case of the Eastern Mediterranean region since today is facing historical challenges in the energy sector. The first challenge concerns the potentially large oil and natural gas deep sea fields recently discovered in the Eastern Mediterranean seabed. The second challenge is the growing integration of renewable energy sources (RES), primarily based on solar energy, in the region's electricity generation systems. It is, therefore, crucial that the region can develop an adequate and integrated energy strategy taking into consideration these challenges. The goal of such a strategy would be twofold: first, to foster a regional oil and gas industry that can be influential in stimulating the region's long term economic growth and second, to ensure the long-term sustainable and clean energy production.

In view of the above developments, the 1st Conference on Power Options for the Eastern Mediterranean Region (POEM 2012) took place between 19 and 21 November 2012 and became an important meeting point for ideas and knowledge sharing on the technical, economic, and regulatory implications of energy production in the Eastern Mediterranean region. In an international dimension, the conference acted as a catalyst on the transfer of oil, gas, and RES technology advancements and best practices from developed energy markets to the region. Moreover, the conference facilitated the exploration of future business opportunities between international and regional energy sector enterprises, in the fields of oil and gas energy infrastructure and RES projects. Finally, the conference highlighted the necessity of research and development in the further advancement of the energy sector in the Eastern Mediterranean region.

Focusing on a regional and local dimension, the conference provided insights into how local energy players can accommodate the sustainable use of the potential Eastern Mediterranean region's hydrocarbon reserves together with the penetration of solar energy systems in the power electricity generation industry. Moreover, business representatives had a chance to be updated on the latest developments in RES technologies, to evaluate the commercial and financial aspects of these technologies, and to be updated on the energy projects which are expected to be developed during the following years. The workshops and the exhibition, delivered in parallel with the main conference event, also provided the opportunity for the development of potential business opportunities between local and international businesses in the related fields of energy infrastructure development, RES, and exploration and exploitation of oil, natural gas, and industrial scale raw materials derived from natural gas.

The conference was highly successful, with 18 invited and 68 contributed papers, covering a wide range of topics from natural gas transportation and utilization to RES high penetration and integration into power systems. The conference was attended by more than 250 participants from 11 countries 
representing the local and foreign press of the region, the stakeholders of the political and energy fields, the experts of the energy industry, engineers, economists, investors, academics, and oil and gas exploration stakeholders. In the conference, the two presidential candidates for the 2013 presidential elections, Dr. George Lillikas and Dr. Stavros Malas, as well as the representative of Mr. Nicos Anastasiades, Mr. Averof Neophytou, were honorary speakers. Furthermore, Mr. Nicolas Papadopoulos, Chairman of the Financial and Budgetary Committee, addressed the conference, whereas a keynote lecture was given by Mr. Nicos Rolandis, former Minister of Foreign Affairs and former Minister of Commerce and Industry. All the papers which were submitted have been rigorously refereed, which always takes time but ensures that the papers which have been finally accepted for publication are of a consistently high standard. The current conference proceedings include a selection of the best reviewed manuscripts presented during the POEM 2012 Conference.

\title{
Acknowledgments
}

The editors would like to extend their thanks to many people who helped to make the conference successful and these proceedings possible. The work of the referees is gratefully acknowledged and, last but certainly not least, all the invited and contributing presenters, without whose efforts the conference could not have been successful as it was. Lastly special thanks go to Conference Papers in Energy for publishing the present conference proceedings.

\author{
Andreas Poullikkas \\ Philip Demokritou \\ Constantinos Sourkounis \\ Yousef Al-Assaf
}



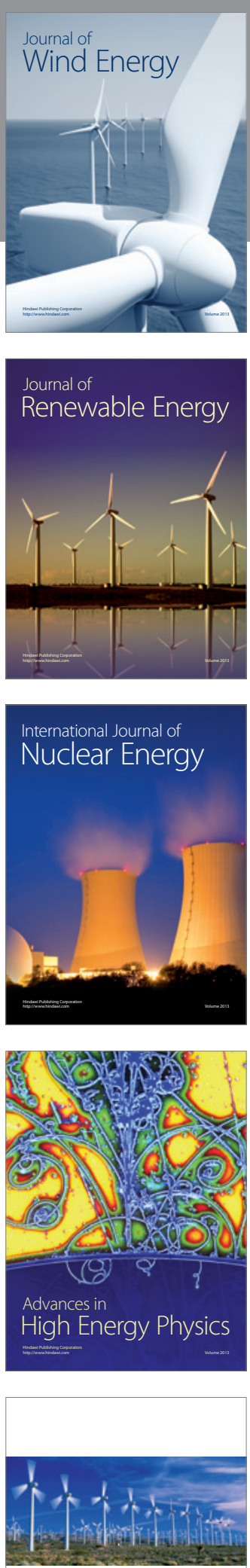

ISRN

Renewable Energy
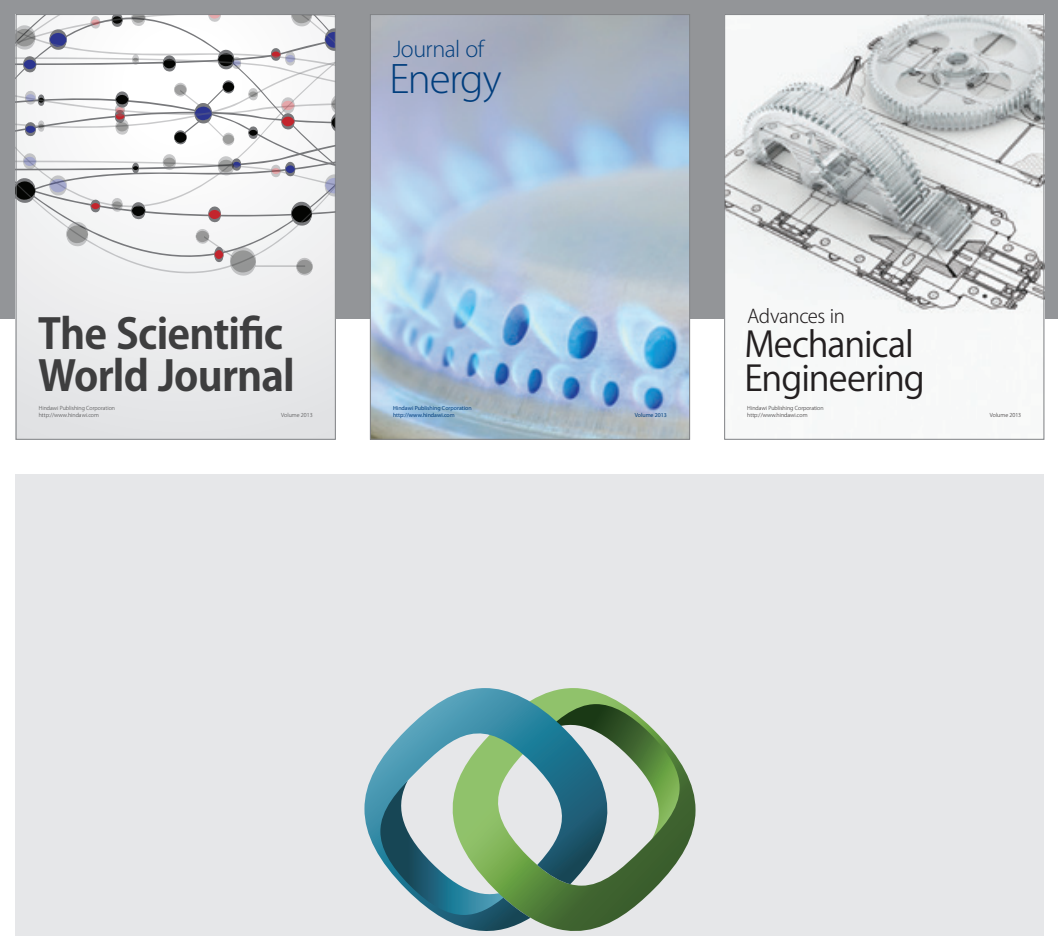

\section{Hindawi}

Submit your manuscripts at http://www.hindawi.com
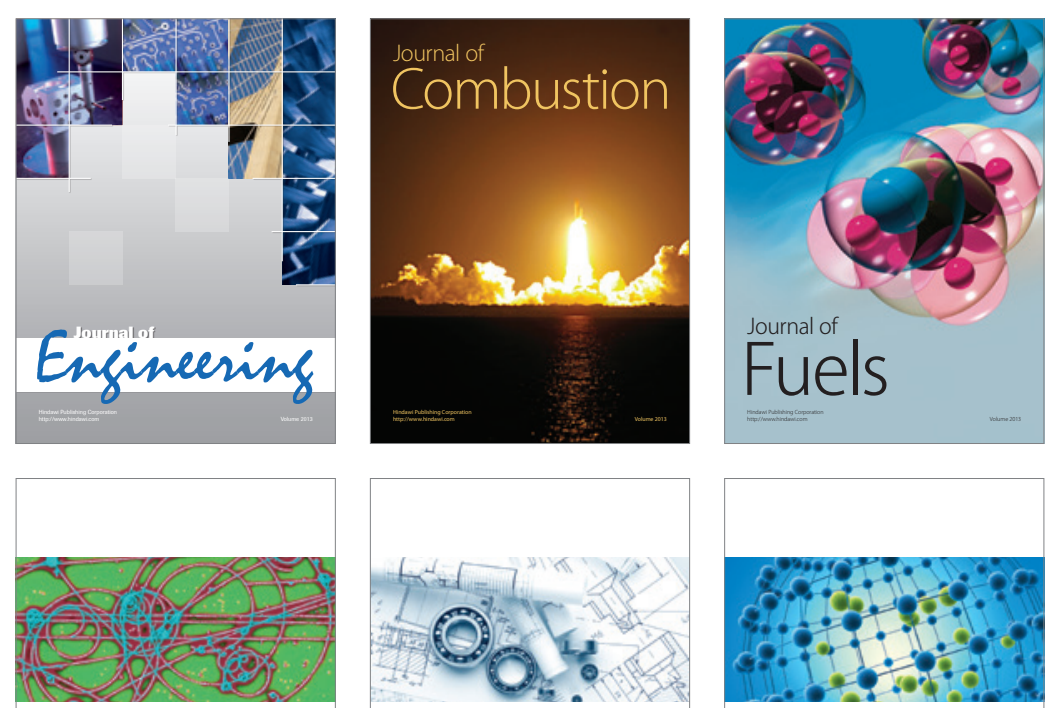

ISRN

High Energy Physics

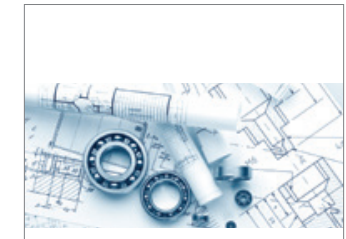

ISRN

Mechanical

Engineering

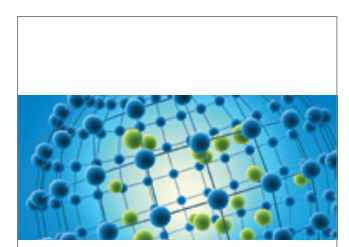

ISRN

Chemical

Engineering
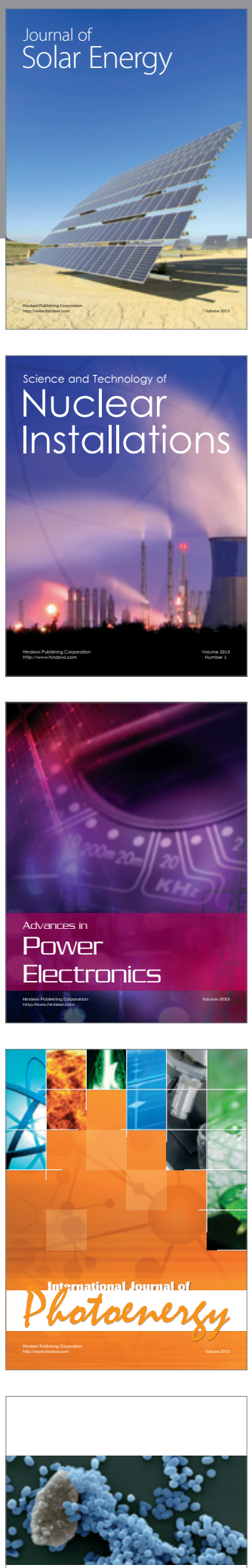

ISRN

Biotechnology 

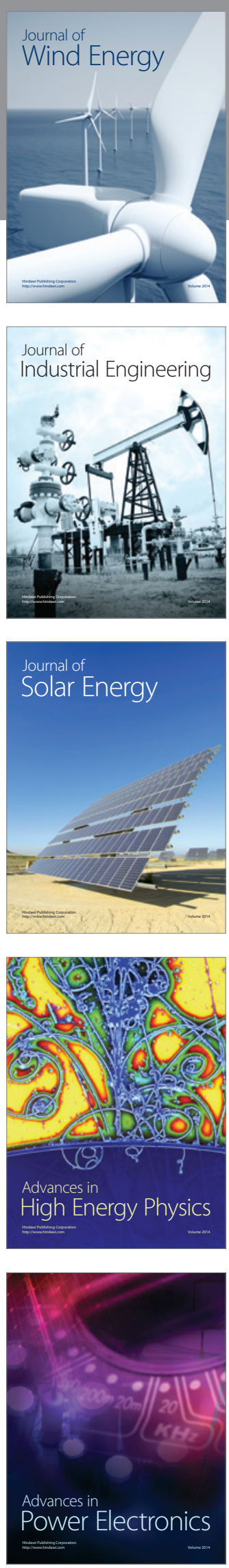
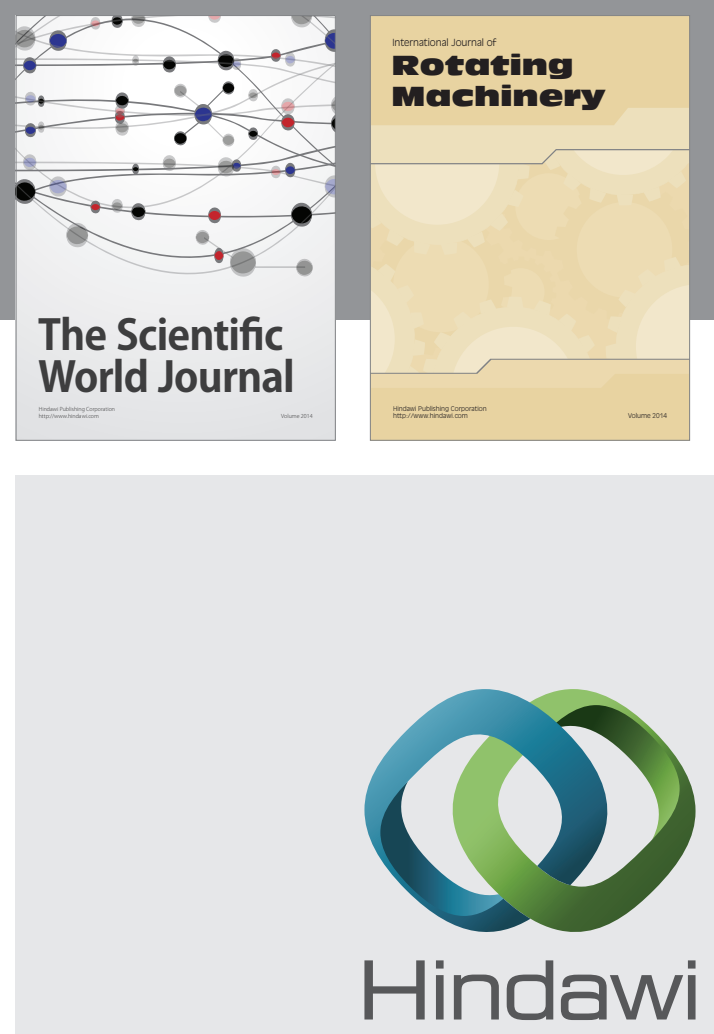

Submit your manuscripts at

http://www.hindawi.com
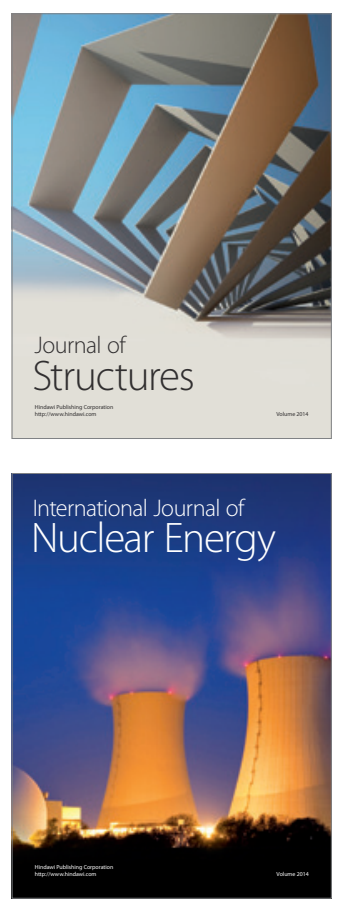
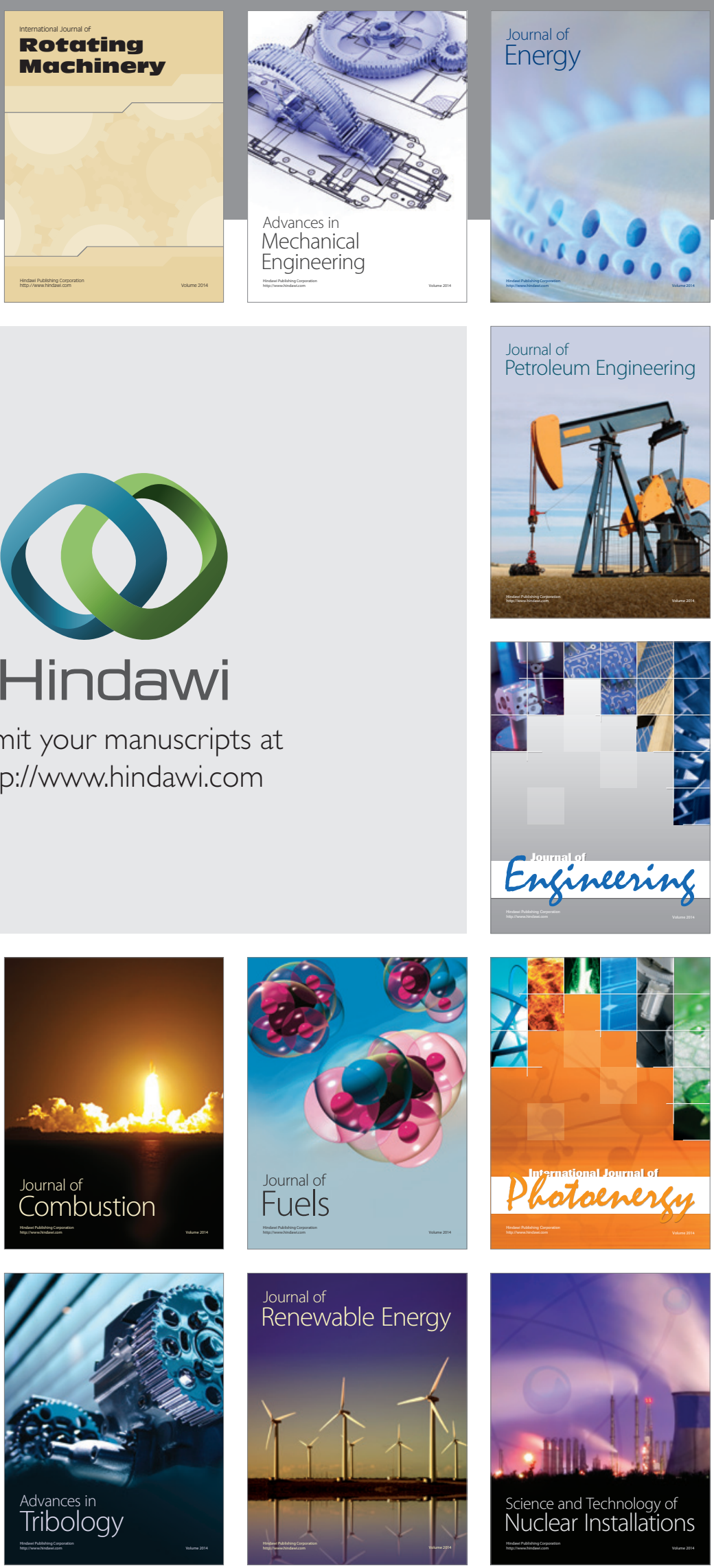